\title{
Cutaneous Side Effects and Transepidermal Water Loss To Gefitinib: A Study of 11 Patients
}

Franky Chandra $(\mathbb{0} \cdot$ Dendi Sandiono $\cdot$ Unwati Sugiri $\cdot$

Oki Suwarsa $\cdot$ Hendra Gunawan

Received: October 21, 2016 / Published online: December 21, 2016

(C) The Author(s) 2016. This article is published with open access at Springerlink.com

\section{ABSTRACT}

Introduction: Cutaneous side effects caused by epidermal growth factor receptor (EGFR) inhibitors occurred in $45-100 \%$ of patients which may lead to therapy modification or interruption. This study aimed to evaluate cutaneous side effects and transepidermal water loss (TEWL) values in non-small cell lung carcinoma (NSCLC) patients who received gefitinib EGFR inhibitor.

Methods: A descriptive observational study with cross-sectional design and a consecutive sampling method was conducted from 1

Enhanced content To view enhanced content for this article go to http://www.medengine.com/Redeem/ DB47F06074568716.

Electronic supplementary material The online version of this article (doi:10.1007/s13555-016-0163-0) contains supplementary material, which is available to authorized users.

F. Chandra $(\bowtie) \cdot D$. Sandiono · U. Sugiri ·

O. Suwarsa - H. Gunawan

Department of Dermatology and Venereology, Faculty of Medicine, Universitas Padjadjaran-Dr.

Hasan Sadikin General Hospital, Bandung,

Indonesia

e-mail: franky_chandra_87@yahoo.co.id
February to 4 March 2016. Eleven NSCLC patients with EGFR mutation who visited the Hemato-Oncology Clinic/Internal Medicine Department, Dr. Hasan Sadikin General Hospital, Bandung, Indonesia, were assessed through history taking, physical examination, and TEWL examination using Tewameter.

Results: Ten of the eleven patients experienced cutaneous side effects. The most frequently observed was xerosis cutis (8/10 patients), followed by acneiform eruptions (7/10 patients), and paronychia (3/10 patients). None of these patients experienced hair changes, mucositis, or drug hypersensitivity. Mean TEWL value of these patients was higher than normal $\left(11.205 \pm 1.881 \mathrm{~g} / \mathrm{m}^{2} / \mathrm{h}\right)$.

Conclusions: Patients who received gefitinib EGFR inhibitor experienced cutaneous side effects including xerosis cutis, acneiform eruptions, and paronychia, and have mean TEWL values higher than normal. Therefore, it might affect the skin barrier function.

Keywords: Cutaneous side effects; Epidermal growth factor receptor inhibitor; Transepidermal water loss 


\section{INTRODUCTION}

Lung carcinoma is one of the leading causes of worldwide mortality [1-3]. One type, non-small cell lung carcinoma (NSCLC), accounts for 85\% of all lung cancers [4]. Prior studies have demonstrated the important role of epidermal growth factor receptor (EGFR), a tyrosine kinase growth factor family transmembrane glycoprotein [5-7], in which gene mutation happens in $40-80 \%$ of all NSCLC patients $[1,4,8]$.

Gefitinib (Iressa ${ }^{\circledR}$ ) is an oral tyrosine kinase EGFR inhibitor $[2,9,10]$ approved by the Food and Drug Administration, USA, as the monotherapy for both local and metastatic NSCLC [11, 12]. Cutaneous toxicities are the most common forms of EGFR inhibitor side effects [13], affecting approximately $45-100 \%$ of patients [13, 14] and varying from papulopustular rashes on the face and upper side trunk to xerosis cutis, paronychia, hair disorder, and pruritus [14, 15], leading to treatment modification or interruption in $8-17 \%$ of patients [14]. These side effects are related to the EGFR expression role in promoting the proliferation, survival, motility, and regulation of the differentiation and keratinization [16] of human skin cells [17], such as keratinocytes [18], corneocytes, sweat glands and hair follicles [5].

Transepidermal water loss is a measurement of the absolute rate of body water loss which acts as a parameter reflecting permeability barrier status and which may discover disturbances in the skin protective function at an early stage, even before they are visible [19]. Due to the limited number of clinical studies on the cutaneous side effects and TEWL value measurements in patients receiving EGFR inhibitor, the authors were interested to conduct this study.

\section{METHODS}

A descriptive observational study with cross-sectional design and a consecutive sampling method was conducted from 1 February to 4 March 2016. We collected NSCLC patients from the Hemato-Oncology Clinic/Internal Medicine Department, Dr. Hasan Sadikin General Hospital, Bandung, Indonesia, medical records. We included all patients with positive EGFR mutation who were on gefitinib as the current main therapy (and had been diagnosed and treatment has been started prior to the study) and those who signed the informed consent form. We excluded patients who had other dermatologic disorder histories before gefitinib consumption or on the examination location (volar surface of both arms); those who used topical medication, medical devices, and other occlusive substances on examination location; those who did not follow-up; and those who refused to participate in this study. Patients were classified according to WHO age groups and their treatment intervals.

History taking and physical examination were conducted while patients were in resting phase $(20 \mathrm{~min})$ before the TEWL value measurement. A Tewameter TM 300, (Khazaka ${ }^{\circledR}$ 2003) was used to measure TEWL values in $30 \mathrm{~s}$, thrice on the volar surface of both arms, at room temperature $20-22{ }^{\circ} \mathrm{C}$ and air humidity 40-60\%. Patient bilateral arm TEWL average value was calculated, with a normal lower arm surface TEWL range value reference of $2.26 \pm 1.36 \mathrm{~g} / \mathrm{m}^{2} / \mathrm{h}$. All procedures followed were in accordance with the ethical 
standards of the responsible committee on human experimentation (institutional approval from Medical Research Ethical Committee, Medical Faculty-Universitas Padjadjaran/Dr. Hasan Sadikin General Hospital) and with the Helsinki Declaration of 1964, as revised in 2013. Written informed consent was obtained from all patients to be included in the study.

\section{RESULTS}

\section{Participants}

The Hemato-Oncology Clinic/Internal Medicine Department recorded that there were 37 NSCLC patients using gefitinib by the year 2014. At the time this study was conducted, 16 patients were confirmed dead, another 14 patients did not make follow-up visits or had no valid contact number and address, another 2 patients had moved out of the town, and the last 1 stopped her gefitinib regimen. Only 4 former patients came to our clinic and agreed to participate in our study along with other 7 new patients. There were 2 new patients who were reluctant to participate (see Fig. 1).

Eleven lung adenocarcinoma patients with positive EGFR mutation, consisted of 6 male and 5 female patients within age group $>40$ years old were included in this study. The youngest patient was 43 and the eldest was 84 years (mean $62.18 \pm 13.27$ ). Most patients were $>65$. The shortest interval of gefitinib consumption was 1 week, while the longest was 18 months (average $10.27 \pm 6.14$ months). Most participants had been using gefitinib for $>6$ months (7/11 patients). According to physical examination, 10 patients has experienced at least one cutaneous disorder manifestation. One male patient who belonged to the $>65$ years group had been using gefitinib for just 1 week and had not complained of any cutaneous side effect, which was confirmed by his physical examination (see Table 1).

\section{Cutaneous Side Effects and TEWL Results}

Female patients had more xerosis cutis (5/5 patients) and paronychia (2/5 patients), while male patients experienced more acneiform eruption (4/5 patients). Xerosis cutis and acneiform eruption were the two most common cutaneous findings in every age group, while paronychia was detected mostly in the 40-44 and 60-64 age groups. As mentioned previously, one patient who had only been using gefitinib for 1 week ( $<1$ month) showed no cutaneous side effects manifestation (see Tables 2, 3).

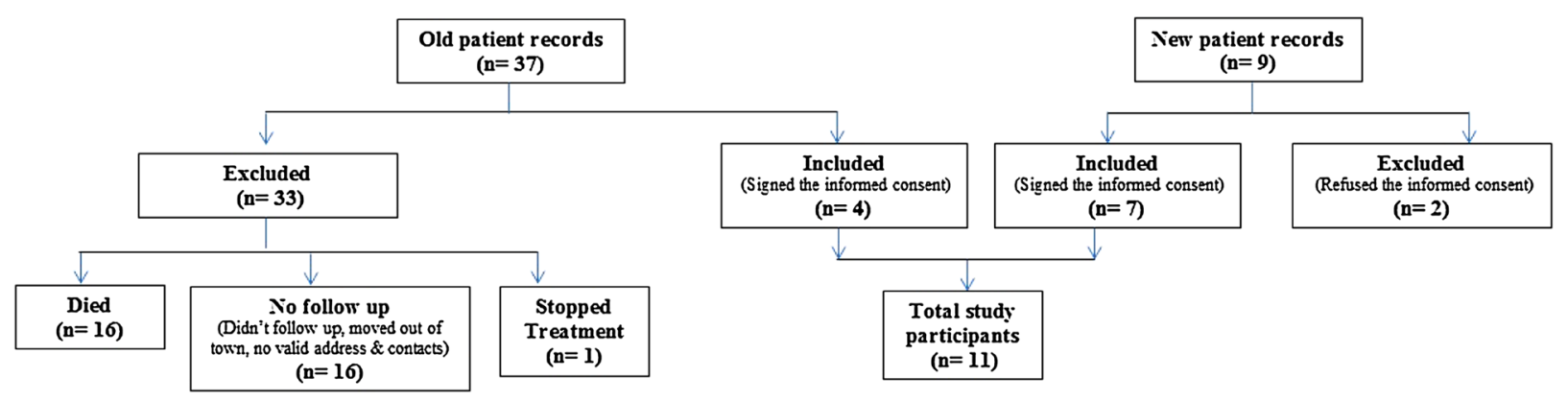

Fig. 1 Study participants enrolment 
Table 1 Cutaneous side effect manifestations examination result

\begin{tabular}{|c|c|c|}
\hline Characteristic & $(n=11)$ & Note \\
\hline \multicolumn{3}{|l|}{ Sex } \\
\hline Male & 6 & \\
\hline Female & 5 & \\
\hline \multicolumn{3}{|c|}{ Age groups (years) } \\
\hline $40-44$ & 1 & Mean (SD): 62.18 (13.27) \\
\hline $45-49$ & 1 & Median: 62.00 \\
\hline $50-54$ & 2 & Interval: $43-84$ \\
\hline $55-59$ & 0 & \\
\hline $60-64$ & 3 & \\
\hline$\geq 65$ & 4 & \\
\hline \multicolumn{3}{|c|}{ Gefitinib consumption interval (months) } \\
\hline$<1$ & 1 & \\
\hline $1-2$ & 0 & Mean (SD): $10.27(6.14)$ \\
\hline $2-3$ & 1 & Median: 12.00 \\
\hline $3-4$ & 0 & Interval: $0-18$ \\
\hline $4-5$ & 0 & \\
\hline $5-6$ & 2 & \\
\hline$>6$ & 7 & \\
\hline \multicolumn{3}{|c|}{ Cutaneous disorder } \\
\hline Yes & 10 & \\
\hline No & 1 & \\
\hline
\end{tabular}

Table 2 Cutaneous side effect manifestations examination result

\begin{tabular}{ll}
\hline Cutaneous side effect manifestations & Total $(\boldsymbol{n = 1 0})$ \\
\hline Xerosis cutis & 8 \\
Acneiform eruption & 7 \\
Paronychia & 3 \\
Others (hair disorder, mucositis, & 0 \\
$\quad$ hypersensitivity reactions) & \\
\hline
\end{tabular}

The mean TEWL value measurement on both volar surfaces of patients was $11.205( \pm 1.881)$ $\mathrm{g} / \mathrm{m}^{2} / \mathrm{h}$ (see Table $\mathrm{S} 1$ in the supplementary material for details). Mean TEWL measurement values were higher in male than in female patients. Based on age group, TEWL values were highest in 40-44 years group compared to other age groups. TEWL value was also the highest in the gefitinib consumption group of 5-6 months and lowest in the group of $<1$ month (see Table 3).

\section{DISCUSSION}

\section{Cutaneous Side Effect Manifestations in NSCLC Patients with EGFR Mutation Who Received Gefitinib}

This study showed that $10 / 11$ patients experienced cutaneous side effects which confirmed the previous literature, Wang et al. [17], who revealed that $67.6 \%$ of lung carcinoma patients with unknown EGFR mutation status who received gefitinib in Taiwan experienced cutaneous side effects. According to Cohen et al. [12], the level of EGFR mutation was assumed to be associated with cutaneous side effects, because of the elevated EGFR inhibition in the skin tissue. Some patients were more susceptible to side effects of EGFR inhibition, due to DNA polimorphism of normal cells and carcinoma.

The most common cutaneous side effects findings in this study were xerosis cutis, followed by acneiform eruption, and paronychia (see Figs. 2, 3, 4). According to Roe, xerosis cutis developed in $100 \%$ of patients after 6 months consuming the EGFR inhibitor [20]. This might have happened 
Table 3 Cutaneous side effects and TEWL results categorized by participant baseline characteristics

\begin{tabular}{|c|c|c|c|c|}
\hline $\begin{array}{l}\text { Variable total } \\
(n=11)\end{array}$ & $\begin{array}{l}\text { Xerosis cutis } \\
(n=8)\end{array}$ & $\begin{array}{l}\text { Acneiform eruption } \\
(n=7)\end{array}$ & $\begin{array}{l}\text { Paronychia } \\
(n=3)\end{array}$ & $\begin{array}{l}\text { Mean bilateral TEWL } \\
\text { values }\left(\mathrm{g} / \mathrm{m}^{2} / \mathrm{h}\right)\end{array}$ \\
\hline \multicolumn{5}{|l|}{ Sex group } \\
\hline Male $(n=6)$ & 3 & 4 & 1 & $11.64( \pm 2.34)$ \\
\hline Female $(n=5)$ & 5 & 3 & 2 & $10.68( \pm 1.17)$ \\
\hline \multicolumn{5}{|l|}{ Age group (years) } \\
\hline $40-44(n=1)$ & 1 & 1 & 1 & $15.72( \pm 0)$ \\
\hline $45-49(n=1)$ & 1 & 1 & 0 & $11.12( \pm 0)$ \\
\hline $50-54(n=2)$ & 1 & 1 & 0 & $11.03( \pm 0.59)$ \\
\hline $55-59(n=0)$ & 0 & 0 & 0 & - \\
\hline $60-64(n=3)$ & 2 & 1 & 2 & $10.78( \pm 1.71)$ \\
\hline$\geq 65(n=4)$ & 3 & 3 & 0 & $10.5( \pm 1.44)$ \\
\hline \multicolumn{5}{|c|}{ Gefitinib consumption interval (months) } \\
\hline$<1(n=1)$ & 0 & 0 & 0 & $8.55( \pm 0)$ \\
\hline $1-2(n=0)$ & 0 & 0 & 0 & - \\
\hline $2-3(n=1)$ & 0 & 1 & 0 & $11.98( \pm 0)$ \\
\hline $3-4(n=0)$ & 0 & 0 & 0 & - \\
\hline $4-5(n=0)$ & 0 & 0 & 0 & - \\
\hline $5-6(n=2)$ & 2 & 2 & 1 & $13( \pm 3.84)$ \\
\hline$>6(n=7)$ & 6 & 4 & 2 & $10.96( \pm 1.01)$ \\
\hline
\end{tabular}

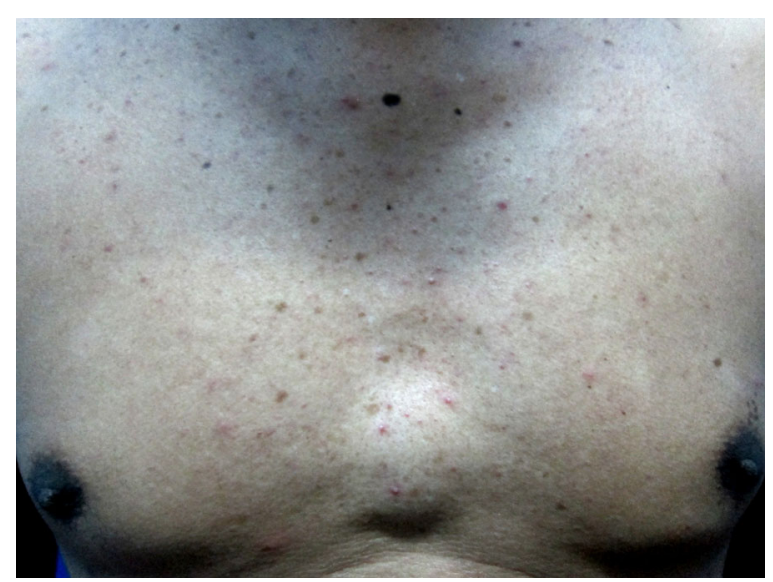

Fig. 2 Acneiform eruption on patient's chest because, in normal conditions, it took 14 days for epidermal cells to reach the stratum corneum [14], and thus keratinocyte differentiation disorder due to EGFR inhibitor causing xerosis cutis was a late-onset side effect $[14,21]$.

Acneiform eruption in this study was found in almost every age group and was more common in male patients, as demonstrated by previous studies, due to the outdoor activities that exposed males to ultra violet (UV) light more than females [22]. Ultra violet light exposure resulted in keratinocyte destruction 


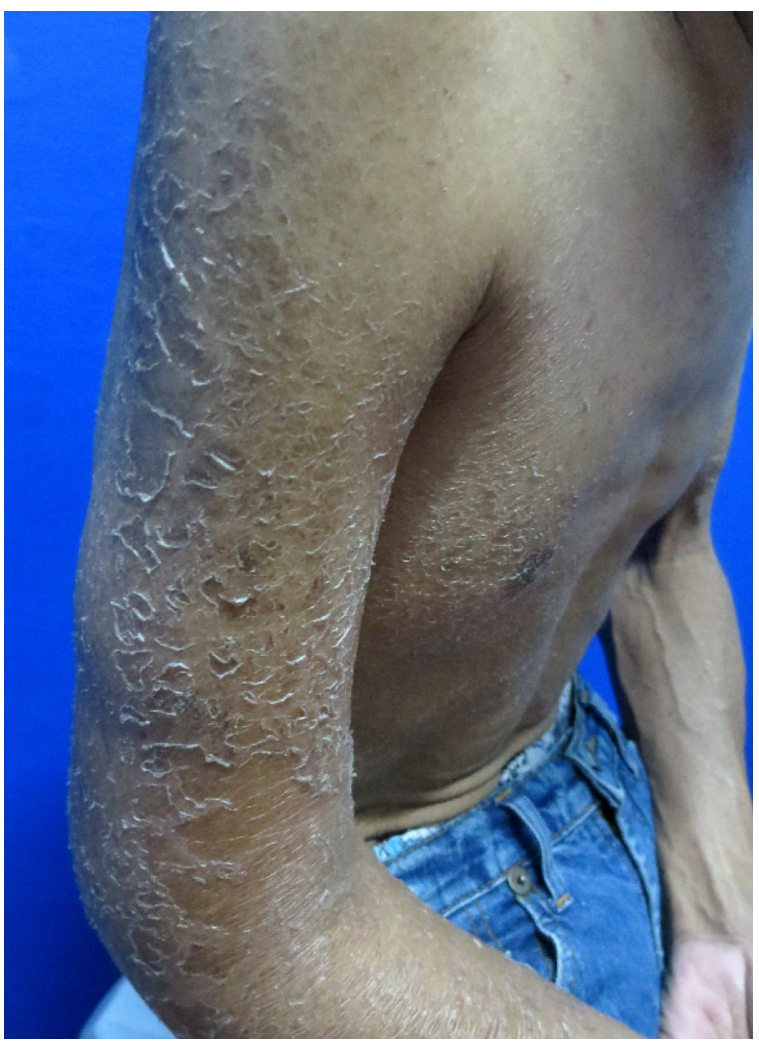

Fig. 3 Xerosis cutis on patient's upper extremity

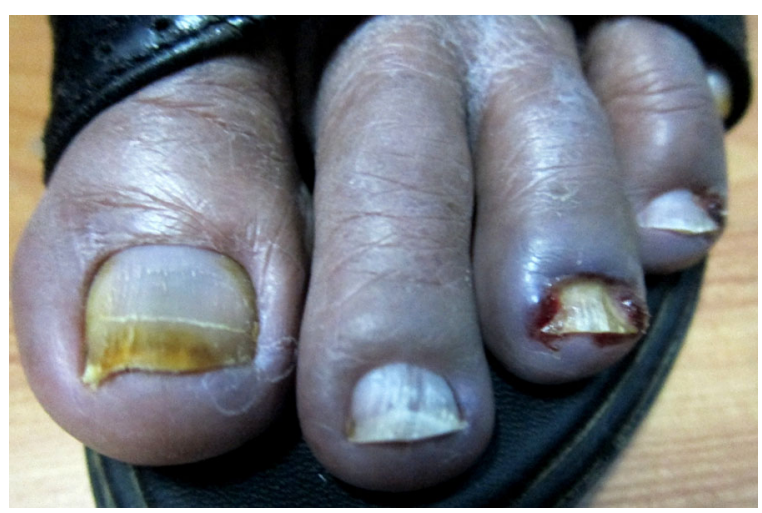

Fig. 4 Paronychia of patient's third toe nail

through photoproducts and reactive oxygen species (ROS) formation. Hence, that effect might become worse when EGFR inhibition occurred simultaneously [14].

Inhibition of EGFR resulted in distortion of skin cell growth, epithelial cells differentiation, and skin protection function
[23], including to UV exposure protection [13]. Moreover, EGFR inhibition led to increased inflamatory chemokin expression which then recruited and resulted in inflammatory cells infiltration, especially in the follicle infundibulum [24].

Wang et al. [17] revealed the correlation between xerosis cutis and paronychia, and that xerosis cutis is a risk factor for paronychia, since xerosis cutis induced by the EGFR inhibitor might cause desquamation with subsequent sticking between the nail plate and the neighboring skin, inducing chronic irritation and inflammation [25]. We confirmed this condition in our study that the patients who had paronychia also experienced xerosis cutis (see Fig. 4).

There were no other cutaneous side effects such as hair changes, mucositis, or drug hypersensitivity to gefitinib observed in our patients in this study. Similar results have been published in other studies of gefitinib treatment. Hair disorder has once been reported, by Santiago et al. [5], with one of seven patients who used erlotinib EGFR inhibitor experiencing hair growth and texture alteration. The hair became thin, brittle or curled. However, none of our participants used erlotinib.

\section{Transepidermal Water Loss Value in NSCLC with EGFR Mutation Who Received Gefitinib}

Mean patient TEWL value in this study increased compared to the normal value range $2.26 \pm 1.36 \mathrm{~g} / \mathrm{m}^{2} / \mathrm{h}$, as a consequence of EGFR inhibition that might cause abnormal keratinocyte differentiation resulting in disturbances of the stratum corneum and sebaceous glands leading to the loss of the epidermal water-retaining function [14]. 
Elevation of TEWL was also reported by Fabbrocini et al. [26] in 33 carcinoma patients who experienced EGFR inhibitor side effects $\left(16.67 \mathrm{~g} / \mathrm{m}^{2} / \mathrm{h}\right)$. However, our study differed from Fabroccini's since we carried out stratification for each patient characteristic group.

Transepidermal water loss value measurement in our study participants (see Table 3) showed a higher value in male patients $\left(11.64 \mathrm{~g} / \mathrm{m}^{2} / \mathrm{h}\right)$ compared to females $\left(10.68 \mathrm{~g} / \mathrm{m}^{2} / \mathrm{h}\right)$. This might have resulted from several influencing factors, such as the use of topical products, exposure to chemicals (including frequency of exposure to solvents and detergents/surfactants), and the degree of skin damage which affected patients skin hydration state [27]. Moreover, sweat and sebaceous gland activities were higher in males [28] and so might have increased the TEWL value [29]. Similar results have been published by Reed et al. [30], who showed mean TEWL values in male patients of $5.1 \pm 0.6 \mathrm{~g} / \mathrm{m}^{2} / \mathrm{h}$ and in female patients of $4.8 \pm 0.4 \mathrm{~g} / \mathrm{m}^{2} / \mathrm{h}$.

Transepidermal water loss value measurements classified by age group in our patients showed the highest value in the 40-44 years age group while the lowest one was in the $>65$ years age group. This happened because the participant with the highest TEWL value who experienced the most severe form of xerosis cutis was in the 40-44 years age group, while the one participant who did not experience skin disorder was included in the $>65$ years age group. This condition had an impact on the participants' mean TEWL value in those age groups.

Classified by gefitinib consumption interval, the lowest TEWL value was found in patients using gefitinib for less than a month and the highest in the 5-6 months interval (see Table 3). As mentioned before, the only patient who had been using gefitinib for $<1$ month had not experienced any cutaneous effects which might also affect the TEWL value. On the other hand, one of two patients who has been on gefitinib therapy for 5-6 months experienced the most cutaneous side effects and had the highest TEWL value.

\section{Limitations}

The limited number of samples in our study might not fully reflect the real population distribution of cutaneous side effects due to gefitinib treatment. Future studies should be conducted with longer observation times and records of both TEWL value measurements and cutaneous side effects from examinations in the pre- and post-gefitinib therapy period to provide better descriptions of EGFR inhibitior-induced cutaneous side effects.

\section{CONCLUSIONS}

Gefitinib has been approved for the treatment of NSCLC in many countries. However, its use is associated with cutaneous side effects of varied severity. Health care providers should acknowledge and understand that these conditions can be managed in order to allow the continuation of the therapy. Multidisciplinary management is essential to prevent severe symptoms, to increase patient compliance, consequently increasing the survival of patients with a better quality of life.

\section{ACKNOWLEDGEMENTS}

No funding support or sponsorship was received for this study or the publication of this article. All named authors meet the International Committee of Medical Journal Editors (ICMJE) 
criteria for authorship for this manuscript, take responsibility for the integrity of the work as a whole, and have given final approval to the version to be published.

Disclosures. Franky Chandra, Dendi Sandiono, Unwati Sugiri, Oki Suwarsa, and Hendra Gunawan declare that they have no conflict of interest.

Compliance with Ethics Guidelines. All procedures followed were in accordance with the ethical standards of the responsible committee on human experimentation (from Medical Research Ethical Committee, Medical Faculty-Universitas Padjadjaran/Dr.Hasan Sadikin General Hospital) and with the Helsinki Declaration of 1964, as revised in 2013. Written informed consent was obtained from all patients for being included in the study.

Data Availability. All data generated or analyzed during this study are included in this published article as supplementary information files.

Open Access. This article is distributed under the terms of the Creative Commons Attribution-NonCommercial 4.0 International License (http://creativecommons.org/licenses/ by-nc/4.0/), which permits any noncommercial use, distribution, and reproduction in any medium, provided you give appropriate credit to the original author(s) and the source, provide a link to the Creative Commons license, and indicate if changes were made.

\section{REFERENCES}

1. Keefe DMK, Bateman EH. Tumor control versus adverse events with targeted anticancer therapies. Nat Rev Clin Oncol. 2012;9:98-109.
2. Reck M, Gatzemeier U. Gefitinib ('Iressa'):a new therapy for advanced non-small-cell lung cancer. Respir Med. 2005;99:298-307.

3. Heuvers ME, Hegmans JP, Stricker BH, Aerts JG. Improving lung cancer survival;time to move on. BMC Pulm Med. 2012;12:77-81.

4. Herbst RS, Heymach JV, Lippman SM. Lung cancer. N Engl J Med. 2008;359:1367-80.

5. Santiago F, Reis JP, Gonçalo M, Figueiredo A. Adverse cutaneous reactions to epidermal growth factor receptor inhibitors-a study of 14 patients. An Bras Dermatol. 2011;86(3):483-90.

6. Eaby B, Culkin A, Lacouture ME. An interdisciplinary consensus on managing skin reactions associated with human epidermal growth factor receptor inhibitors. Clin J Oncol Nurs. 2008;12(2):283-90.

7. Giovanini $\mathrm{M}$, et al. Clinical significance of skin toxicity due to EGFR-targeted therapies. J Oncol. 2009;30:1-8.

8. Kitamura H, Yazawa T, Okudela K, Shimoyamada H, Sato H. Molecular and genetic pathogenesis of lung cancer:differences between small-cell and non-small-cell carcinomas. Open Pathol J. 2008;2:106-14.

9. Lee SH, Jeong SK, Ahn SK. An update of the defensive barrier function of skin. Yonsei Med J. 2006;47(3):293-306.

10. Diaz A, Lage A. Therapies based on inhibitors of the epidermal growth factor receptor:reaching for the future. Biotecnol Apl. 2007;24:10-8.

11. Heidary N, Naik H, Burgin S. Chemotherapeutic agents and the skin:an update. J Am Acad Dermatol. 2008;58:545-70.

12. Cohen EEW, et al. Phase II trial of gefitinib $250 \mathrm{mg}$ daily in patients with recurrent and/or metastatic squamous cell carcinoma of the head and neck. Clin Cancer Res. 2005;11(23):8418-24.

13. Lynch TJ, et al. Epidermal growth factor receptor inhibitor-associated cutaneous toxicities: an evolving paradigm in clinical management. Oncol. 2007;12:610-21.

14. Lacouture ME. Mechanisms of cutaneous toxicities to EGFR inhibitors. Nat Rev Cancer. 2006;6:803-12.

15. Burtness B, Goldwasser MA, Flood W, Mattar B, Forastiere AA. Phase III randomized trial of cisplatin plus placebocompared with cisplatin plus cetuximab in metastatic recurrent head and neck 
cancer: an eastern cooperative oncology group study. J Clin Oncol. 2005;23:8646-54.

16. Han SS, et al. Investigation of papulopustular eruptions caused by cetuximab treatment shows altered differentiation markers and increases in inflammatory cytokines. $\mathrm{Br} \mathrm{J}$ Dermatol. 2010;162:371-9.

17. Wang S, et al. Skin manifestations of gefitinib and the association with survival of advanced non-small-cell lung cancer in Taiwan. Dermatol Sin. 2011;29:13-8.

18. Araki T, et al. Review of the treatment of non-small cell lung cancer with gefitinib. Clin Med Insight:Oncol. 2012;6:407-21.

19. Verdier-Sévrain S, Bonté F. Skin hydration:a review on its molecular mechanisms. J Cosmet Dermatol. 2007;6:75-82.

20. Roe E, et al. Description and management of cutaneous side effects during cetuximab or erlotinib treatments: a prospective study of 30 patients. J Am Acad Dermatol. 2006;55:429-37.

21. Balagula Y, Lacouture ME, Cotliar JA. Dermatologic toxicities of targeted anticancer therapies. J Support Oncol. 2010;8:149-61.

22. Shah SR, Walsh TL, Williams CB, Soefje SA. Gefitinib (ZD1839, Iressa ${ }^{\circledR}$ ):a selective epidermal growth factor receptor-tyrosine kinase inhibitor. J Oncol Pharm Pract. 2003;9:151-60.

23. Guttman-Yassky E, et al. Characterisation of the cutaneous pathology in non-small cell lung cancer
(NSCLC) patients treated with the EGFR tyrosine kinase inhibitor erlotinib. Eur J Cancer. 2010;46:2010-9.

24. Abdullah SE, Haigentz Jr M., Piperdi B. Dermatologic toxicities from monoclonal antibodies and tyrosine kinase inhibitors against EGFR: pathophysiology and management. Dermatol Res Pract. 2012:1-10.

25. Seagert S, Custom VE. Clinical signs, pathophysiology and management of skin toxicity during therapy with epidermal growth factor receptor inhibitors. Ann Oncol. 2005;16(9):1425-33.

26. Fabbrocini G, et al. Chemotherapy and skin reactions. J Exp Clin Canc Res. 2012;31:50-6.

27. Plessis J. International guidelines for the in vivo assessment of skin properties in non-clinical settings:part 2. Transepidermal water loss and skin hydration. Skin Res Technol. 2013;19:265-78.

28. Jacobi U, Gautier J, Sterry W, Lademann J. Gender-related differences in the physiology of the stratum corneum. Dermatology. $2005 ; 211: 312-7$.

29. Kleesz P, Darlenski R, Fluhr JW. Full-body skin mapping for six biophysical parameters: baseline values at 16 anatomical sites in 125 human subjects. Skin Pharmacol Physiol. 2012;25:25-33.

30. Reed JT, Ghadially R, Elias PM. Skin type, but neither race nor gender, influence epidermal permeability barrier function. Arch Dermatol. 1995;131:1134-8. 